\title{
Inactivation of nuclear factor KB by MIP-based drug combinations augments cell death of breast cancer cells
}

This article was published in the following Dove Press journal:

Drug Design, Development and Therapy

\author{
Menaga Subramaniam' \\ Su Ki Liew' \\ Lionel LA $\ln ^{2}$ \\ Khalijah Awang S $^{3,4}$ \\ Niyaz Ahmed ${ }^{5}$ \\ Noor Hasima Nagoor ${ }^{1,6}$ \\ 'Institute of Biological Science \\ (Genetics \& Molecular Biology), \\ Faculty of Science, University of \\ Malaya, Kuala Lumpur, Malaysia; \\ ${ }^{2}$ Department of Biotechnology, \\ Faculty of Applied Sciences, UCSI \\ University, Kuala Lumpur, Malaysia; \\ ${ }^{3}$ Centre for Natural Product Research \\ and Drug Discovery (CENAR), \\ University of Malaya, Kuala Lumpur, \\ Malaysia; ${ }^{4}$ Department of Chemistry, \\ Faculty of Science, University of \\ Malaya, Kuala Lumpur, Malaysia; \\ ${ }^{5}$ Pathogen Biology Laboratory, \\ Department of Biotechnology \\ and Bioinformatics, University of \\ Hyderabad, Hyderabad, India; ${ }^{6}$ Centre \\ for Research in Biotechnology for \\ Agriculture (CEBAR), University of \\ Malaya, Kuala Lumpur, Malaysia
}

Correspondence: Noor Hasima Nagoor Institute of Biological Science (Genetics \& Molecular Biology), Faculty of Science, University of Malaya, Lembah Pantai,

50603 Kuala Lumpur, Malaysia

Tel +60379675921

Fax +60 379675908

Email hasima@um.edu.my
Background: Drug combination therapy to treat cancer is a strategic approach to increase successful treatment rate. Optimizing combination regimens is vital to increase therapeutic efficacy with minimal side effects.

Materials and methods: In the present study, we evaluated the in vitro cytotoxicity of double and triple combinations consisting of 1'S-1'-acetoxychavicol acetate (ACA), Mycobacterium indicus pranii (MIP) and cisplatin (CDDP) against 14 various human cancer cell lines to address the need for more effective therapy. Our data show synergistic effects in MCF-7 cells treated with MIP:ACA, MIP:CDDP and MIP:ACA:CDDP combinations. The type of interaction between MIP, ACA and CDDP was evaluated based on combination index being $<0.8$ for synergistic effect. Identifying the mechanism of cell death based on previous studies involved intrinsic apoptosis and nuclear factor kappa $\mathrm{B}(\mathrm{NF}-\mathrm{\kappa B})$ and tested in Western blot analysis. Inactivation of NF- $\kappa \mathrm{B}$ was confirmed by $\mathrm{p} 65$ and $\mathrm{I} \kappa \mathrm{B} \alpha$, while intrinsic apoptosis pathway activation was confirmed by caspase-9 and Apaf-1 expression.

Results: All combinations confirmed intrinsic apoptosis activation and NF- $\kappa \mathrm{B}$ inactivation. Conclusion: Double and triple combination regimens that target induction of the same death mechanism with reduced dosage of each drug could potentially be clinically beneficial in reducing dose-related toxicities.

Keywords: Mycobacterium indicus pranii, 1'S-1'-acetoxychavicol acetate, drug combination, nuclear factor $\kappa \mathrm{B}$

\section{Introduction}

Globally, cancers figure among the leading causes of morbidity and mortality, with 14 million new cases and 8.2 million cancer-related deaths in 2012, and the number of new cases is expected to increase to 22 million within the next 2 decades. ${ }^{1}$ Anticancer drugs are important means to mitigate the impact of cancer progression and mortality. The development of cancer is generally associated with modification of many genes causing alteration of multiple pathways and biochemical activities in a cell. As a result, in many cases, single drug treatment often fails to produce the desired therapeutic effect. ${ }^{2}$ Therefore, combination regimens may provide the best hope for effective treatment outcomes.

Combination chemotherapy provides the opportunity to minimize metabolic and clinical side effects because of usage of low doses in comparison to single-agent therapy. ${ }^{3}$ While the cancer adaptation process can be delayed when multiple drugs with different molecular targets are applied, multiple drugs that target one single cellular pathway would be able to function synergistically for both higher therapeutic efficacy and target selectivity. ${ }^{4}$ Development of drug resistance in tumor cells can also be overcome by 
using combination drug therapy. ${ }^{5}$ Moreover, the advantages of combinations include the ability to replace current standalone anticancer therapies, which tend to result in resistance over repeated treatments. ${ }^{6}$ In this study, we propose a combination of 1'S-1'-acetoxychavicol acetate (ACA) as a chemosensitizer, heat-killed bacteria Mycobacterium indicus pranii (MIP $\mathrm{HKB})$ as an immune potentiator and the commercial drug cisplatin (CDDP) in various human cancer cell lines.

ACA is a phenylpropanoid that is naturally found in various plant species of the Zingiberaceae family. ${ }^{7}$ It has been reported to exhibit antiulcer, ${ }^{8}$ antiallergic, ${ }^{9}$ anti-inflammatory ${ }^{10}$ and anticancer effects. ${ }^{11}$ ACA was also reported to inhibit the constitutive activation of nuclear factor kappa B (NF- $\mathrm{KB})$ through suppression of IKK $\alpha / \beta$ activation modulated through dysregulation of the NF- $\kappa$ B pathway. ${ }^{12}$ In a recent study, ACA in combination with CDDP was reported to sensitize cervical cancer cells, resulting in a subsequent increase in its cytotoxic effects. ${ }^{13}$

CDDP is one of the most widely used platinum-based anticancer drugs against various cancers involving sarcoma, soft tissue, bones, muscles and blood vessels. Apart from inducing apoptotic cell death, ${ }^{14} \mathrm{CDDP}$ is also reported to have a direct impact on genomic DNA to form DNA adducts ${ }^{15}$ that subsequently inhibit DNA replication and RNA transcription. ${ }^{16}$ It has been used in cancer patients for the past 45 years; however, its efficiency is often accompanied by toxic side effects and tumor resistance, which in turn leads to immunosuppression. ${ }^{17,18}$

The saprophytic bacterium MIP stimulates cell-mediated responses and the immune system in patients suffering from a number of diseases such as leprosy, ${ }^{19}$ human immunodeficiency virus, ${ }^{20}$ psoriasis $^{21}$ and cancer, specifically against bladder and non-small-cell lung cancer. ${ }^{22,23}$ In our recent preliminary study, we have reported cytotoxic and apoptotic effects of MIP HKB on various cancer types. ${ }^{24}$ However, the efficacy of MIP in combination with other drugs has not been reported. As MIP, ACA and CDDP individually display antitumor activity toward cancer, double and triple combinations of these agent and drugs may translate into improved therapies. Therefore, this study reports on the double and triple combinatorial usages between these three drug/agents in order to synergistically chemosensitize and eradicate targeted malignancies in anticancer treatment.

\section{Materials and methods}

\section{Materials}

Dulbecco's Modified Eagle's Medium (DMEM) supplemented with $4.5 \mathrm{~g}$ glucose/L and $300 \mathrm{mg} / \mathrm{L}$-glutamine was purchased from Hyclone Laboratories Inc., Logan, Utah and Roswell Park Memorial Institute 1640 (RPMI 1640) media were purchased from Thermo Fisher Scientific, Waltham,
MA, USA. Fetal bovine serum (FBS) was purchased from Lonza Inc. (Allendale, NJ, USA). Middlebrook 7H10 agar and $7 \mathrm{H} 9$ broth were obtained from Sigma-Aldrich, Co., St Louis, MO, USA. ACA was provided by the Centre for Natural Product Research and Drug Discovery, Department of Chemistry, University of Malaya, Malaysia. CDDP and tumor necrosis factor alpha (TNF- $\alpha$ ) were purchased from EMD Millipore (Billerica, MA, USA). MTT reagents were obtained from EMD Chemicals Inc. MIP was provided by Prof Dr Niyaz Ahmed, Department of Biotechnology and Bioinformatics, School of Life Sciences, University Hyderabad, India. Bovine serum albumin (BSA) was obtained from EMD Millipore. The primary antibodies mouse-antihuman

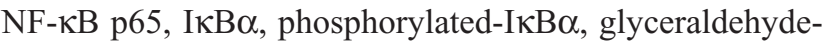
3-phosphate dehydrogenase (GAPDH), Apaf-1 and caspase-9 were purchased from Cell Signaling Technology, Danvers, MA, USA. All other chemicals were of analytical grade and commercially available.

\section{Cell culture}

A total of fourteen human cancer cell lines and one normal breast epithelial cell line were used in this study: breast adenocarcinoma (MCF-7 and MDA-MB-231), hepatocyte carcinoma (HepG2), cervical carcinoma (CaSki, SiHa and HeLa S3), prostate carcinoma (PC-3 and DU-145), lung adenocarcinoma (A549 and SK-LU-1), oral squamous cell carcinoma (ORL-48 and ORL-115) and bladder carcinoma (RT-112 and EJ-28). Breast epithelial (MCF-10A) was used as normal cells. All cell lines were obtained from American Type Culture Collection (ATCC), Manassas, VA, USA except human oral cancer cell lines, which were obtained from Cancer Research Initiative Foundation (CARIF, Selangor, Malaysia). HepG2, CaSki, SiHa, HeLa S3, ORL-48 and ORL-115 cells were cultured in DMEM, while MCF-7, PC-3, MDA-MB231, A549, RT-112, EJ-28 and DU-145 cells were cultured in RPMI 1640, supplemented with 10.0\% (v/v) FBS. MCF-10A was grown in serum-free mammary epithelial basal media (MEBM; Lonza, Basel, Switzerland) supplemented with cholera toxin $(100 \mathrm{ng} / \mathrm{ml})$. SK-LU-1 cells were cultured in MEM- $\alpha$ supplemented with $10 \%(\mathrm{v} / \mathrm{v})$ heat-inactivated FBS. All cells were grown as monolayers and were maintained in a humidified $\mathrm{CO}_{2}$ incubator at $37^{\circ} \mathrm{C}$ in $5.0 \% \mathrm{CO}_{2}$ and $95.0 \%$ air.

\section{Bacterial culture}

MIP was cultured in Middlebrook (MB) 7H9 broth supplemented with $0.2 \%$ glycerol, $0.05 \%$ Tween- $80,10 \%$ albumindextrose complex enrichment and incubated at $37^{\circ} \mathrm{C}, 100 \mathrm{rpm}$ agitation until $1.5 \mathrm{OD}_{600}$. MIP HKB fraction was prepared as stated in a previous study. ${ }^{24}$ 


\section{Disc diffusion assay}

Disc diffusion assays were performed to identify bacterial inhibition by ACA and CDDP. MIP at a density $\sim 6.0 \times 10^{9}$ MIP cells $/ \mathrm{mL}$ at $1.5 \mathrm{OD}_{600}$ were spread onto MB $7 \mathrm{H} 10$ agar-coated plates. Sterile filter discs $(\sim 0.6 \mathrm{~cm})$ were placed on the agar surface in the middle. A total amount of $10 \mu \mathrm{L}$ aliquot of ACA (20.0 mM), CDDP (300 mM), neomycin (0.16 mM) and dimethyl sulfoxide (DMSO) were loaded onto the discs and then incubated at $37^{\circ} \mathrm{C}$, for 4 days before analysis.

\section{Cytotoxicity assay for standalone treatment}

Cell growth inhibition upon treatment with a single drug (MIP HKB or ACA or CDDP) was evaluated based on the MTT assay. Briefly, $1.0 \times 10^{4}$ cells/well were seeded in 96-well plates $(100 \mu \mathrm{L} /$ well), incubated overnight and treated with ACA $(0-50 \mu \mathrm{M})$ or CDDP $(0-160 \mu \mathrm{M})$ or MIP $(0-100 \mu \mathrm{L} /$ $1.0 \times 10^{6} \mathrm{MIP}$ cells $/ \mathrm{mL}$ ) at various concentrations and then incubated for 24 hours. A total amount of $20 \mu \mathrm{L}$ of MTT reagent $(5.0 \mathrm{mg} / \mathrm{mL})$ was added to each well. The plate was left on a shaker for 10 minutes and incubated in the dark at $37^{\circ} \mathrm{C}$. After 1 hour of incubation, the spent medium containing excess dye was aspirated, and $200 \mu \mathrm{L}$ of DMSO was added to dissolve the purple formazan precipitates. Results were obtained using a microtiter plate reader (Sunrise; Tecan Sunrise ${ }^{\circledR}$, Männedorf, Switzerland) to detect absorbance at a test wavelength of $570 \mathrm{~nm}$ and a reference wavelength of $650 \mathrm{~nm}$. From absorbance data obtained, a graph was plotted employing the following equation: Viability $(\%)=[100 \%-$ cytotoxicity $(\%)]$, where cytotoxicity $(\%)=[($ absorbance value of solvent - absorbance value of drug/agent)/absorbance value of untreated cells] $\times 100 \%$. $\mathrm{IC}_{50}$ and $\mathrm{IC}_{25}$ values for all three single agents were determined from the graph at $50 \%$ and $25 \%$ cell viability, respectively.

\section{Double and triple combination treatment}

Double combinations of the MIP:ACA and MIP:CDDP at various molar concentrations were tested for their killing effects on various human cancer cells using the MTT assay as described in "standalone drug treatment" section with a few modifications. The $\mathrm{IC}_{25}$ obtained for each drug in standalone treatment was used as the maximum concentration in combination regime. In MIP:ACA combination, $\mathrm{ACA}$ was used at a fixed $\mathrm{IC}_{25}$ concentration, while MIP HKB was used in increasing concentrations from 0 to $\mathrm{IC}_{25}$. Similarly, for MIP:CDDP combinations, CDDP was used at a fixed $\mathrm{IC}_{25}$ concentration, while MIP HKB was used in increasing concentrations from 0 to $\mathrm{IC}_{25}$. Molar concentration for both MIP:ACA and MIP:CDDP combinations did not exceed $\mathrm{IC}_{50}$. For triple combination regime of MIP, ACA and CDDP, determination of their cell-killing effects was carried out using $\mathrm{IC}_{10}$ of each component. In triple combination, $\mathrm{IC}_{10}$ values of ACA and CDDP were maintained while MIP was tested in increasing concentrations from 0 to $\mathrm{IC}_{10}$. Molar concentration of MIP:ACA:CDDP combination did not exceed $\mathrm{IC}_{30}$. After 24 hours of incubation, MTT assay was performed to compare and determine the survival rate of treated cells.

\section{Multiple drug effect analysis}

The type of combination for double and triple regimens and degree of synergy were assessed based on combination index (CI) calculations according to the method based on the doseeffect relationship as described in the paper by Chou and Talalay ${ }^{25}$ The formula used for calculating the CI of MIP:ACA and MIP:CDDP is CI=(D1c/D1)+(D2c/D2) and the formula used for determining the $\mathrm{CI}$ of triple combination is $\mathrm{CI}=(\mathrm{D} 1 \mathrm{c} / \mathrm{D} 1)+$ $(\mathrm{D} 2 \mathrm{c} / \mathrm{D} 2)+(\mathrm{D} 3 \mathrm{c} / \mathrm{D} 3)$, where D1, D2 and D3 are the doses for each drug and agent alone that inhibit $50 \%$, and D1c, D2c and D3c are the doses for each drug/agent in a combination that inhibits the same $50 \%{ }^{26} \mathrm{CI}$ indicates additivity when $\mathrm{CI}=0.8-1.2$, synergism when $\mathrm{CI}<0.8$ and antagonism when $\mathrm{CI}>1.2$.

\section{Western blot analysis}

A total of $2.0 \times 10^{6}$ cells $/ \mathrm{mL}$ were treated in six-well plates with double and triple combination regimens, and total proteins were extracted using the NE-PERW nuclear and cytoplasmic extraction kit according to the manufacturer's protocol. Protein concentration was quantified and normalized using the Quick Start Bradford Protein Assay Kit 2 (Bio-Rad Laboratories Inc., Hercules, CA, USA) according to the manufacturer's protocol. Fractionation was done using sodium dodecyl sulfate-polyacrylamide gel electrophoresis and electrotransferred onto nitrocellulose membranes. All membranes were blocked with $5 \% \mathrm{w} / \mathrm{v}$ BSA, $1 \times$ Tris-buffered saline and $0.1 \%$ Tween-20 at room temperature with gentle shaking for 90 minutes and incubated with primary antibodies:

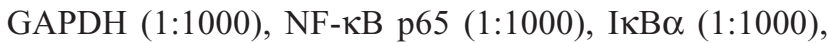
p-IкB $\alpha$ (1:1000), Apaf-1 (1:1000) and caspase-9 (1:1000) overnight at $4{ }^{\circ} \mathrm{C}$, followed by detection using horseradish peroxidase-conjugated secondary antibodies (Cell Signaling), and Super Signal West Pico chemiluminescent substrate. Images were captured using the Fusion FX7 imaging system (Vilber Lourmat, Eberhardzell, Germany). Normalization of protein concentration was carried out against GAPDH as a control. Relative intensities of all bands were quantified using ImageJ v1.43 analysis software (NIH, Bethesda, MD, USA).

\section{Statistical analyses}

All experiments were carried out in triplicates and presented as mean values $\pm \mathrm{SD}$. Student's $t$-test was used to determine the 
statistical significance of results, where a $P$-value of $\leq 0.05$ was considered significant.

\section{Results}

\section{Disc diffusion assay}

Disc diffusion assay was carried out to identify safe usage of the two drugs together without inhibiting bacterial growth rate. As shown in Figure 1, CDDP- and ACA-treated plates did not produce zone of inhibition around the disc, which indicated that CDDP and ACA at the tested concentrations are safe to be used together with MIP. Neomycin was used as a negative control, where it inhibits MIP growth and produces a zone of inhibition ranging from 3 to $10 \mu \mathrm{g} / \mathrm{mL}$ in a dose-dependent manner.

\section{Cytotoxic effect of standalone treatment on various cancer cells}

The $\mathrm{IC}_{50}$ values of MIP HKB, ACA and CDDP as standalone on 14 cancer cells are summarized in Table 1. Results indicated that cells treated with ACA, MIP HKB and CDDP
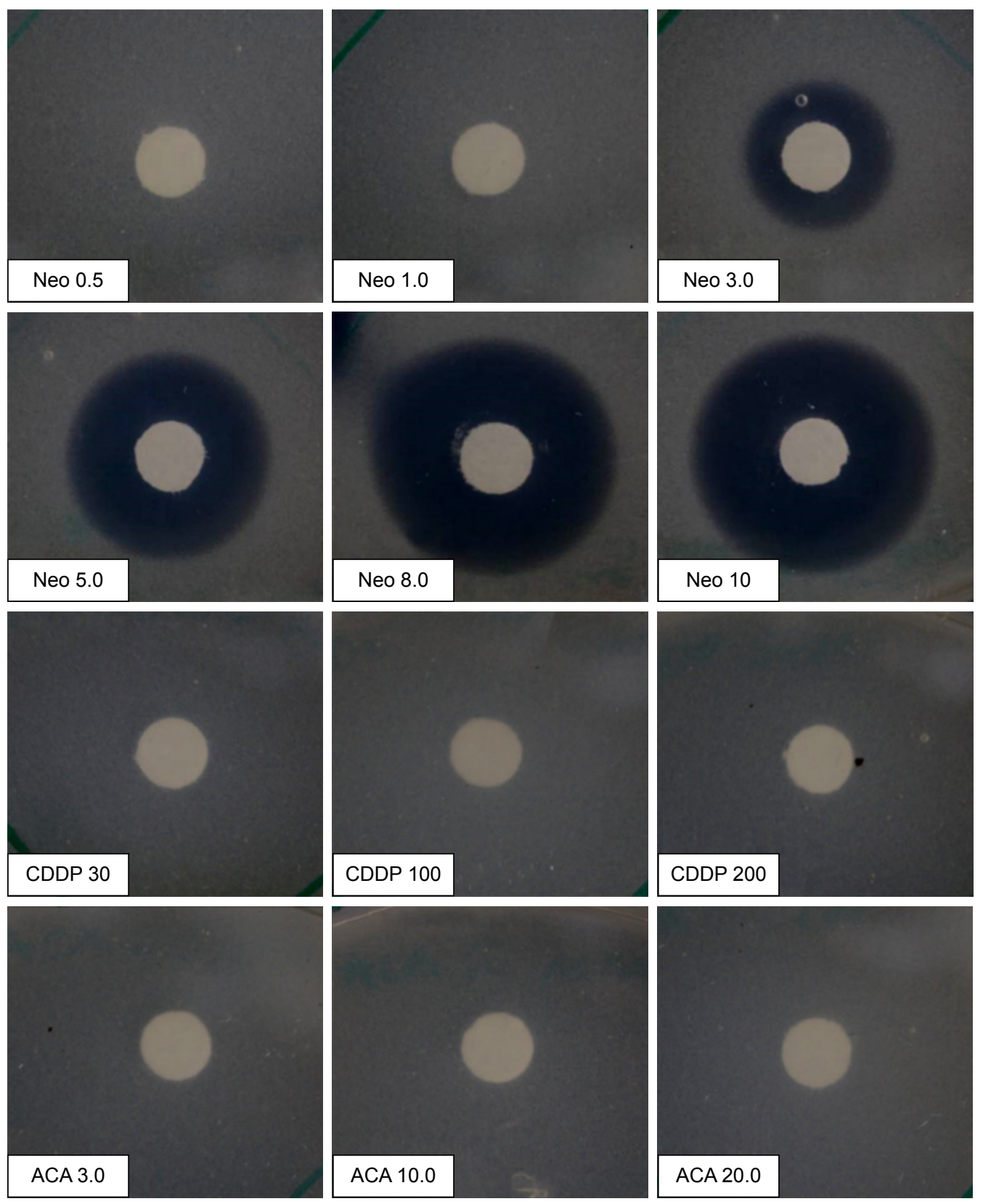

Figure I Disc diffusion assay of MIP against ACA and CDDP with Neo as control.

Note: Middlebrook 7HIO agar plates of discs were impregnated with ACA (3.0, 10.0 and $20.0 \mathrm{mM}), \mathrm{CDDP}(30,100$ and $200 \mathrm{mM})$ and Neo (0.5, I.0, 3.0, 5.0, 8.0 and I0.0 $\mu g / \mathrm{mL})$.

Abbreviations: ACA, acetoxychavicol acetate; CDDP, cisplatin; MIP, Mycobacterium indicus pranii; Neo, neomycin. 
Table I IC I0 $_{50}$ values of standalone treatment at 24 hours

\begin{tabular}{|c|c|c|c|c|}
\hline Cancer type & Cell lines & CDDP $(\mu \mathrm{M})$ & $\begin{array}{l}\text { MIP HKB }\left(\mu \mathrm{L} /\left[1.0 \times 10^{6}\right]\right. \\
\text { MIP cells } / \mathrm{mL})\end{array}$ & ACA $(\mu M)$ \\
\hline \multirow[t]{2}{*}{ Breast } & MDA-MB-23I & $41.6 \pm 23.4$ & $15.4 \pm 0.1$ & $4.8 \pm 0.4$ \\
\hline & MCF-7 & $63 \pm 2.3$ & $12 \pm 0.7$ & $30 \pm 0.3$ \\
\hline \multirow[t]{3}{*}{ Cervical } & CaSki & $51.9 \pm 6.4$ & $15.9 \pm 1.8$ & $13 \pm 0.7$ \\
\hline & $\mathrm{SiHa}$ & $66 \pm 1.3$ & $47.3 \pm 7.6$ & $4.5 \pm 0.3$ \\
\hline & HeLa S3 & $34.3 \pm 3.5$ & $21.1 \pm 2.2$ & $12 \pm 0.6$ \\
\hline \multirow[t]{2}{*}{ Lung } & A549 & $52.2 \pm 1.5$ & $14.3 \pm 1.3$ & $26.5 \pm 6.2$ \\
\hline & SK-LU-I & $\mathrm{n} / \mathrm{a}^{\#}$ & $7.8 \pm 2.8$ & $26.7 \pm 0.7$ \\
\hline \multirow[t]{2}{*}{ Prostate } & PC-3 & $10.89 \pm 0.8$ & $34.50 \pm 1.6$ & $26.7 \pm 2.3$ \\
\hline & DU-I45 & $44.1 \pm 8$ & $18.4 \pm 1.7$ & $19.5 \pm 2.9$ \\
\hline Liver & HepG2 & $13 \pm 0.5$ & $5.6 \pm 0.2$ & $18 \pm 0.8$ \\
\hline \multirow[t]{2}{*}{ Bladder } & EJ-28 & $14.8 \pm 0.4$ & $51.9 \pm 2$ & $8.2 \pm 0.9$ \\
\hline & RT-I I 2 & $11.02 \pm 0.1$ & $35.53 \pm 3.2$ & $|4| \pm 3.8$. \\
\hline \multirow[t]{2}{*}{ Oral } & ORL-48 & $54.8 \pm 1.5$ & $13.6 \pm 1$ & $25.2 \pm 1.1$ \\
\hline & ORL-II5 & $39.8 \pm 2.7$ & $7.8 \pm 1$ & $7.3 \pm 1.5$ \\
\hline \multirow[t]{3}{*}{ Normal cells } & $\mathrm{HaCat}$ & $80.2 \pm 4.6$ & $23.5 \pm 5.4$ & $\mathrm{n} / \mathrm{a}^{\#}$ \\
\hline & NP-69 & $\mathrm{n} / \mathrm{a}^{\#}$ & $32.9 \pm 1.0$ & $\mathrm{n} / \mathrm{a}^{\#}$ \\
\hline & MCF-IOA & $\mathrm{n} / \mathrm{a}^{\#}$ & $25.7 \pm 0.6$ & $\mathrm{n} / \mathrm{a}^{\#}$ \\
\hline
\end{tabular}

Note: ${ }^{n} \mathrm{n} / \mathrm{a}$ because cell viability was maintained above $50 \%$ after 24 -hour treatment.

Abbreviations: ACA, acetoxychavicol acetate; CDDP, cisplatin; HKB, heat-killed bacteria; MIP, Mycobacterium indicus pranii; n/a, not applicable.

as standalone induced cytotoxicity in a dose-dependent manner. In CDDP-treated cells, a higher level of cytotoxicity was observed in liver (HepG2) and bladder (EJ-28 and RT-112) cancers with $\mathrm{IC}_{50}$ values of $13 \pm 0.5 \mu \mathrm{M}$ (HepG2), $14.8 \pm 0.4 \mu \mathrm{M}(\mathrm{EJ}-28)$ and $11.02 \pm 0.1 \mu \mathrm{M}$ (RT-112). In this study, highest CDDP concentrations were required in MCF-7 $(63 \pm 2.3 \mu \mathrm{M})$ and $\mathrm{SiHa}(66 \pm 1.3 \mu \mathrm{M})$ to achieve $50 \%$ cell killing, which indicates that these cells are less sensitive toward CDDP. In MIP HKB-treated cells, highest cell killing was observed in two cancer types, namely oral (ORL-48; $13.6 \pm 1 \mu \mathrm{L} /\left[1.0 \times 10^{6} \mathrm{MIP}\right.$ cells $\left./ \mathrm{mL}\right]$ and ORL-115; 7.8 \pm 1 $\mu \mathrm{L} /[1.0 \times 106 \mathrm{MIP}$ cells $/ \mathrm{mL}])$ and liver $(\mathrm{HepG} 2 ; 5.6 \pm 0.2$ $\mu \mathrm{L} /[1.0 \times 106 \mathrm{MIP}$ cells $/ \mathrm{mL}])$. Most of the other cancer cells recorded $\mathrm{IC}_{50}$ of $20 \mu \mathrm{L} /\left(1.0 \times 10^{6} \mathrm{MIP}\right.$ cells $\left./ \mathrm{mL}\right)$ when treated with MIP. As observed, ACA recorded the highest sensitivity in cervical (CaSki; $13 \pm 0.7 \mu \mathrm{M}$, SiHa; $4.5 \pm 0.3 \mu \mathrm{M}$ and HeLa S3; $12 \pm 0.6 \mu \mathrm{M}$ ), bladder (EJ-28; $8.2 \pm 0.9$ and RT-112; $14.1 \pm 3.8 \mu \mathrm{M}$ ) and oral (ORL-48; 25.2 $\pm 1.1 \mu \mathrm{M}$ and ORL-115; $7.3 \pm 1.5 \mu \mathrm{M})$ cancer cell lines.

The cytotoxicity level of the two drugs and agent was also tested in normal cells to evaluate their safety. As for MIP $\mathrm{HKB}^{24}$ and $\mathrm{ACA},{ }^{12,27}$ previous studies have reported safe usage in in vitro cell lines and in vivo animal models. In normal cells treated with ACA and CDDP, the $\mathrm{IC}_{50}$ values were not obtained (nonapplicable and denoted as $\mathrm{n} / \mathrm{a}$ ) because the cell viability was maintained above $50 \%$ even after 24 hours treatment at the maximum test concentration. While an $\mathrm{IC}_{50}$ was attained in MIP-treated normal cells, it was considered acceptable for use owing to a much lower $\mathrm{IC}_{50}$ requirement in certain cancer cells such as breast, lung, liver and oral cancer cells.

\section{Synergy of double and triple combinations of MIP,ACA and CDDP against various cancer cells}

We next assessed the synergistic activity of double and triple combinations of MIP HKB, ACA and CDDP over a range of concentrations (up to $\mathrm{IC}_{25}$ for double treatment or $\mathrm{IC}_{10}$ for triple combination) against seven cancer types as listed in Table 2.

In the MIP:ACA double combinations, significant synergistic relationships were observed for all tested cancer cell lines with the exception of additive relationships in PC-3, CaSki, RT-112 and SK-LU-1 cells. In MIP:CDDP double combination, synergistic relationships were observed in all cell lines except additivity in A549, while CaSki, DU-145, SK-LU-1 and ORL-115 show cytotoxicity levels lower than 50\%. In both the MIP:ACA and MIP:CDDP combinations, synergistic relationships as low as 0.2 were achieved.

In triple combination, when combination was carried out using $\mathrm{IC}_{25}$, synergistic relationship was not observed in any cancer cells, and only additive and antagonistic relationship was recorded (Table 3). Interestingly, when triple combination was carried out using a lower dosage ( $\mathrm{IC}_{10}$ of each component), synergism was achieved in all the cancer cells with the exception in CaSki and DU-145 
Table 2 MIP:ACA and MIP:CDDP double combination treatment at I:I ratio on various human cancer cell lines

\begin{tabular}{|c|c|c|c|c|c|c|c|}
\hline \multirow[t]{2}{*}{ Cancer type } & \multirow[t]{2}{*}{ Cell line } & \multicolumn{3}{|c|}{ MIP:ACA (25:25) } & \multicolumn{3}{|c|}{ MIP:CDDP (25:25) } \\
\hline & & $I C_{50}{ }^{a}$ & $\mathrm{Cl}$ & Relation & $I C_{50}{ }^{a}$ & Cl & Relation \\
\hline \multirow[t]{2}{*}{ Breast } & MCF-7 & $0.76 \pm 0.2$ & 0.58 & $S$ & $0.72 \pm 0.1$ & 0.4 & $S$ \\
\hline & MDA-MB-23I & $1.8 \pm 0.1$ & 0.7 & $S$ & $4.4 \pm 0.7$ & 0.4 & $S$ \\
\hline \multirow[t]{3}{*}{ Cervical } & CaSki & $1.4 \pm 0.2$ & 0.9 & $A D$ & $\mathrm{n} / \mathrm{a}$ & $\mathrm{n} / \mathrm{a}$ & $\mathrm{n} / \mathrm{a}$ \\
\hline & $\mathrm{SiHa}$ & $4.1 \pm 0.2$ & 0.3 & $\mathrm{~S}$ & $2.9 \pm 0.3$ & 0.2 & $S$ \\
\hline & HeLaS3 & $2.7 \pm 0.7$ & 0.2 & $S$ & $1.3 \pm 0.1$ & 0.2 & $S$ \\
\hline \multirow[t]{2}{*}{ Lung } & A549 & $1.2 \pm 0.2$ & 0.7 & $\mathrm{~S}$ & $2.7 \pm 1.0$ & 0.9 & $A D$ \\
\hline & SK-LU-I & $1.6 \pm 0.1$ & I.I & $A D$ & $\mathrm{n} / \mathrm{a}$ & $\mathrm{n} / \mathrm{a}$ & $\mathrm{n} / \mathrm{a}$ \\
\hline \multirow[t]{2}{*}{ Prostate } & PC-3 & $3.3 \pm 0.1$ & I.I & $A D$ & $3.3 \pm 0.2$ & 0.6 & $S$ \\
\hline & DU-I45 & $1.4 \pm 0.2$ & 0.7 & $S$ & $\mathrm{n} / \mathrm{a}$ & $\mathrm{n} / \mathrm{a}$ & $\mathrm{n} / \mathrm{a}$ \\
\hline Liver & HepG2 & $0.3 \pm 0.2$ & 0.7 & $S$ & $0.32 \pm 0.1$ & 0.6 & $S$ \\
\hline \multirow[t]{2}{*}{ Bladder } & $\mathrm{EJ}-28$ & $4.4 \pm 0.2$ & 0.5 & $S$ & $10.7 \pm 2.7$ & 0.71 & $S$ \\
\hline & RT-III & $2.4 \pm 0.1$ & 0.8 & $A D$ & $2.6 \pm 0.4$ & 0.57 & $S$ \\
\hline \multirow[t]{2}{*}{ Oral } & ORL-48 & $1.7 \pm 0.3$ & 0.3 & $S$ & $2.3 \pm 0.5$ & 0.4 & $S$ \\
\hline & ORL-III & $\mathrm{n} / \mathrm{a}$ & $\mathrm{n} / \mathrm{a}$ & $\mathrm{n} / \mathrm{a}$ & $\mathrm{n} / \mathrm{a}$ & $\mathrm{n} / \mathrm{a}$ & $\mathrm{n} / \mathrm{a}$ \\
\hline Normal cell & MCF-IOA & $\mathrm{n} / \mathrm{a}$ & $\mathrm{n} / \mathrm{a}$ & $\mathrm{n} / \mathrm{a}$ & $\mathrm{n} / \mathrm{a}$ & $\mathrm{n} / \mathrm{a}$ & $\mathrm{n} / \mathrm{a}$ \\
\hline
\end{tabular}

Note: ${ }^{a} \mathrm{C}_{50}\left(\mu \mathrm{L} /\left[1.0 \times 10^{6} \mathrm{MIP}\right.\right.$ cells $\left.\left./ \mathrm{mL}\right]\right)$ shows amount of MIP required to achieve $50 \%$ cell killing at constant ACA or CDDP.

Abbreviations: ACA, acetoxychavicol acetate; AD, additive; CDDP, cisplatin; Cl, combination index; MIP, Mycobacterium indicus pranii; n/a, not applicable; S, synergistic.

prostate cancer cell line. In the A549, SK-LU-1, EJ-28 and ORL-115 cell lines, a 50\% cytotoxicity level was not achieved. Therefore, triple combination at lower dosage works efficiently compared to concentration of $\mathrm{IC}_{25}$ combination in double and triple.

As a result of these double and triple combination analyses, MCF-7 was selected because of the lowest CI values for further identification and evaluation on the mode of action involved. The double and triple combination effects were also tested in normal human breast epithelial, MCF-10A at a 24 -hour treatment, which showed $65 \%$ cell viability in both MIP:ACA and MIP:CDDP double combinations and $60 \%$ cell viability in triple combination (Figure $\mathrm{S} 1$ ). In all tested combinations, $\mathrm{IC}_{50}$ was not obtained. Therefore, we can conclude that combination therapy minimally affects noncancerous human breast cell. Thus, Western blot was carried out to validate the involvement of NF- $\mathrm{KB}$ regulated proteins in MCF-7. In addition, activation of intrinsic apoptosis was also analyzed using Apaf-1 and caspase-9 antibodies.

Table 3 MIP:ACA:CDDP triple combination treatment on various human cancer cell lines

\begin{tabular}{|c|c|c|c|c|c|c|c|}
\hline \multirow[t]{2}{*}{ Cancer type } & \multirow[t]{2}{*}{ Cell line } & \multicolumn{3}{|c|}{ MIP:ACA:CDDP (25:25:25) } & \multicolumn{3}{|c|}{ MIP:ACA:CDDP (10:10:10) } \\
\hline & & $I C_{50}{ }^{a}$ & Cl & Relation & $I C_{50}{ }^{a}$ & $\mathbf{C l}$ & Relation \\
\hline \multirow[t]{2}{*}{ Breast } & MCF-7 & $0.6 \pm 0.4$ & 0.92 & $A D$ & $0.27 \pm 0.3$ & 0.41 & $S$ \\
\hline & MDA-MB-23I & $1.8 \pm 0.1$ & 1.0 & $A D$ & $1.3 \pm 0.2$ & 0.44 & $\mathrm{~S}$ \\
\hline \multirow[t]{3}{*}{ Cervical } & CaSki & $1.2 \pm 0.1$ & 1.1 & $A D$ & $2.5 \pm 0.5$ & 0.82 & $A D$ \\
\hline & $\mathrm{SiHa}$ & $2.0 \pm 0.7$ & 1.6 & AT & $3.2+0.2$ & 0.4 & $S$ \\
\hline & HeLa S3 & $1.5 \pm 0.1$ & 1.3 & AT & $0.5+0.3$ & 0.7 & $S$ \\
\hline \multirow[t]{2}{*}{ Lung } & A549 & $1.4 \pm 0.1$ & 1.7 & AT & $\mathrm{n} / \mathrm{a}$ & $\mathrm{n} / \mathrm{a}$ & $\mathrm{n} / \mathrm{a}$ \\
\hline & SK-LU-I & $1.4 \pm 0.1$ & 1.9 & AT & $\mathrm{n} / \mathrm{a}$ & $\mathrm{n} / \mathrm{a}$ & $\mathrm{n} / \mathrm{a}$ \\
\hline \multirow[t]{2}{*}{ Prostate } & PC-3 & $4 \pm 0.13$ & 1.7 & AT & $2.9 \pm 0.1$ & 0.48 & $S$ \\
\hline & DU-I 45 & $1.4 \pm 0.1$ & 1.5 & AT & $12+1.6$ & I.I & $A D$ \\
\hline Liver & HepG2 & $0.3 \pm 0.3$ & 1.2 & $A D$ & $0.2+0.1$ & 0.6 & $S$ \\
\hline \multirow[t]{2}{*}{ Bladder } & EJ-28 & $3.5 \pm 0.4$ & 1.0 & $A D$ & $\mathrm{n} / \mathrm{a}$ & $\mathrm{n} / \mathrm{a}$ & $\mathrm{n} / \mathrm{a}$ \\
\hline & RT-I I 2 & $2.0 \pm 0.2$ & 1.3 & AT & $3.5+0.6$ & 0.6 & $S$ \\
\hline \multirow[t]{2}{*}{ Oral } & ORL-48 & $4.4 \pm 0.1$ & I.I & $A D$ & $0.5+1$ & 0.4 & $S$ \\
\hline & ORL-II5 & $3.0 \pm 0.1$ & 1.4 & AT & $\mathrm{n} / \mathrm{a}$ & $n / a$ & $\mathrm{n} / \mathrm{a}$ \\
\hline Normal cell & MCF-IOA & $\mathrm{n} / \mathrm{a}$ & $\mathrm{n} / \mathrm{a}$ & $\mathrm{n} / \mathrm{a}$ & $\mathrm{n} / \mathrm{a}$ & $\mathrm{n} / \mathrm{a}$ & $\mathrm{n} / \mathrm{a}$ \\
\hline
\end{tabular}

Note: ${ }^{a} \mathrm{C}_{50}\left(\mu \mathrm{L} /\left[1.0 \times 10^{6} \mathrm{MIP}\right.\right.$ cells $\left.\left./ \mathrm{mL}\right]\right)$ shows amount of MIP required to achieve $50 \%$ cell killing at constant ACA or CDDP.

Abbreviations: ACA, acetoxychavicol acetate; AD, additive; AT, antagonistic; CDDP, cisplatin; Cl, combination index; MIP, Mycobacterium indicus pranii; n/a, not applicable; S, synergistic. 


\section{The combination of MIP,ACA and CDDP activates caspase- 9 and Apaf-I}

Morphologic changes in MCF-7 cells upon combination treatment showed induction of apoptotic cell death. Previous study has demonstrated that MIP could induce mitochondriamediated apoptosis in mouse peritoneal macrophages in vitro. ${ }^{28}$ Thus, in this study we have tested intrinsic apoptotic protein expression in MIP combinations using Apaf-1 and caspase- 9 to validate intrinsic apoptosis-mediated cell death. As shown in Figure 2, caspase-9 cleavage products were observed in increasing concentrations, while procaspase- 9 was reduced upon treatment with the two drugs and agent combinations at 6 hours in MCF-7. Similarly, Apaf-1 expression was observed in MIP, ACA and CDDP double and triple combinations. Significant increase in apoptosis was achieved when cleaved caspase- 9 was significantly expressed at 6 hours between double and triple combinations of MIP:ACA vs MIP:ACA:CDDP and MIP:CDDP vs MIP:ACA:CDDP.

\section{Effect of MIP,ACA and CDDP in downregulating the expression of NF- $\kappa B$ proteins in vitro}

The occurrence of NF- $\mathrm{BB}$ inhibition was monitored with no translocation of p65 from the cytoplasm to the nucleus. Figure 3 revealed a high p65 level in the cytoplasm compared to a low level in the nucleus over 6 hours. This indicated that p65 nuclear localization was perturbed with an increasing treatment exposure time. Also, the NF- $\kappa \mathrm{B}$ inhibitor $\mathrm{I} \kappa \mathrm{B} \alpha$ protein expression was reduced with increased phosphorylated I $\mathrm{KB} \alpha$ levels over 6 hours post-treatment. Moreover, significant increase in NF- $\kappa \mathrm{B}$ inhibition was achieved between double and triple combinations of MIP, ACA and CDDP. p65 level in cytoplasm was significantly increased at 6 hours between double and triple combinations of MIP:ACA vs MIP:ACA:CDDP and MIP:CDDP vs MIP:ACA:CDDP.

As TNF- $\alpha$ is one of the main cytokines that binds to TNF receptors to activate the NF- $\kappa B$ pathway, this study also investigated if both double and triple combinations could suppress TNF- $\alpha$-induced NF- $\kappa$ B activation. MCF-7 was pretreated with TNF- $\alpha$ for 1 hour followed by treatment with MIP, ACA and CDDP double and triple combinations. Western blot analysis indicated that all treatment regimens tested were able to diminish TNF- $\alpha$-based NF- $\kappa$ B activation through low levels of $\mathrm{p} 65$ and higher I $\mathrm{B} \alpha \alpha$ phosphorylated levels in breast cancer cells. Thus, this result suggests that MIP, ACA and CDDP in combination could induce NF- $\kappa B$ inactivation.

\section{Discussion}

In the present study, we investigated the in vitro effects of ACA in combination with MIP and CDDP against various human cancer cell lines. The ability of ACA and CDDP to work together with MIP without diminishing effects on the latter was tested using disc diffusion assay. The cytotoxicity effects for the combinations were obtained using the MTT assay, and data were analyzed based on CI values to determine types of combinatorial relationships. The therapeutic activity of drug combination is not only dependent on the
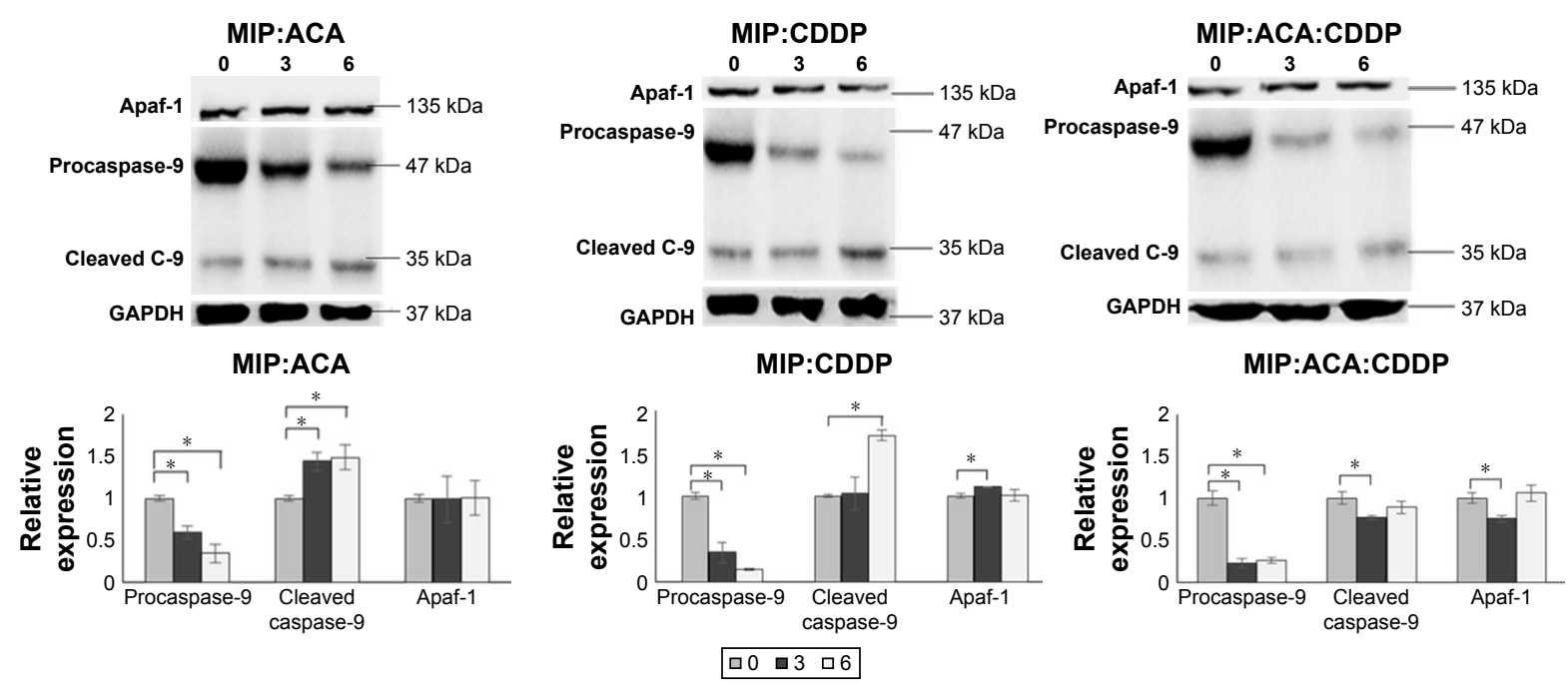

Figure 2 MIP, ACA and CDDP double and triple combination studies stimulates intrinsic apoptosis.

Notes: Cells were treated with MIP:ACA, MIP:CDDP and MIP:ACA:CDDP at 3 and 6 hours followed by Western blot analysis. Normalized quantification of proteins in the double and triple treatments. Two-tailed student's $t$-test: *P<0.05; error bars represent + SD.

Abbreviations: ACA, acetoxychavicol acetate; CDDP, cisplatin; Cleaved C-9, Cleaved Caspase-9; GAPDH, glyceraldehyde-3-phosphate dehydrogenase; MIP, Mycobacterium indicus pranii. 
A

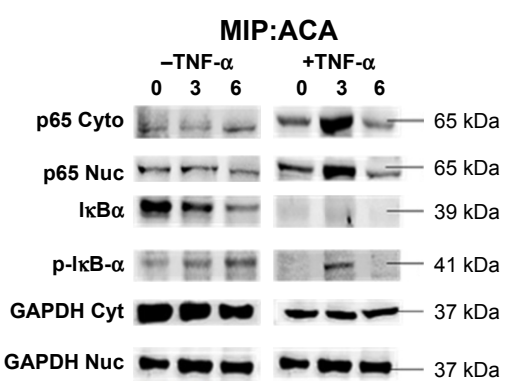

B
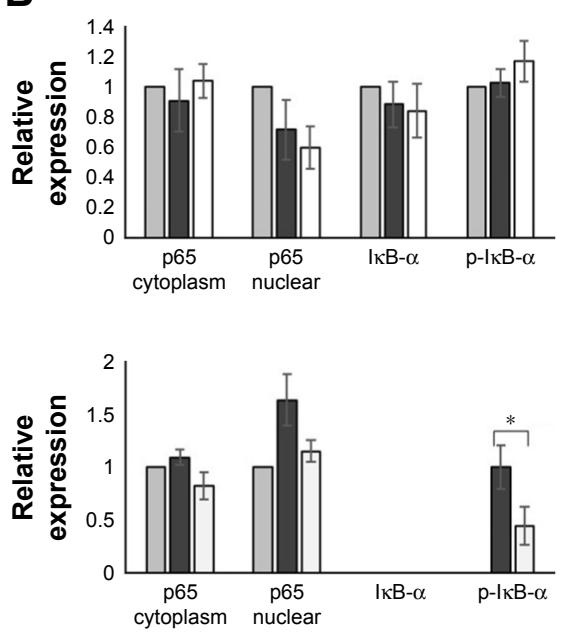

MIP:CDDP

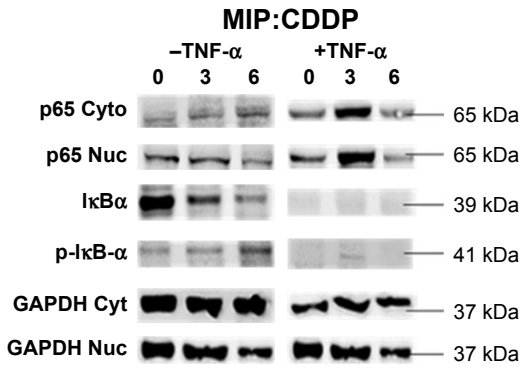

Without TNF- $\alpha$ induction

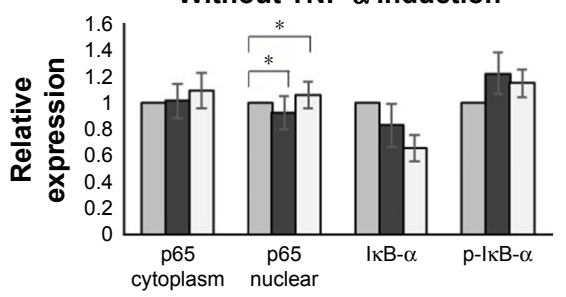

With TNF- $\alpha$ induction

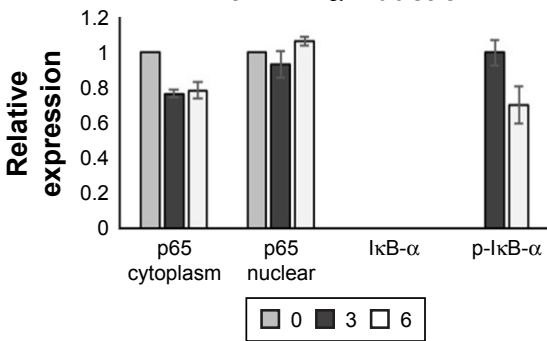

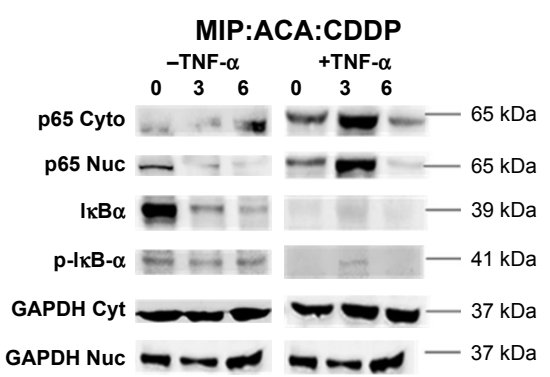
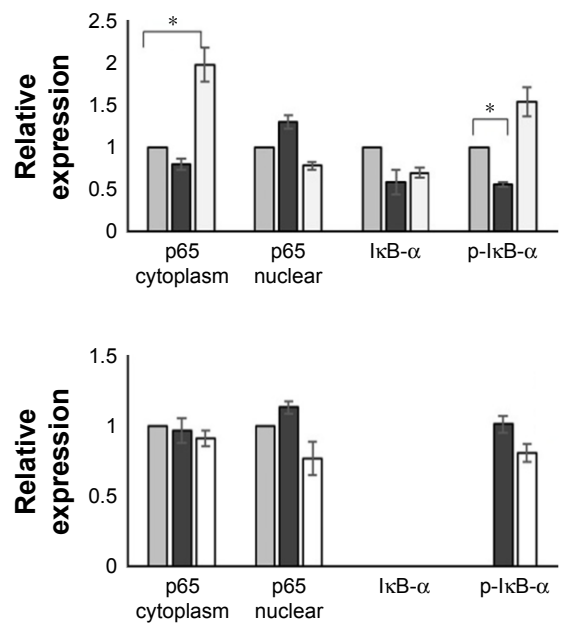

Figure 3 Combinations involving MIP, ACA and CDDP reduced NF- $\kappa B$ activation and inhibited p65 (RelA) nuclear retention in MCF-7 human breast cancer cells. Notes: Cells were treated with MIP:ACA, MIP:CDDP and MIP:ACA:CDDP at 3 and 6 hours in the presence and absence of TNF- $\alpha$. (A) Normalized quantification of NF- $\kappa B$ protein members on double and triple treatments without TNF- $\alpha$ stimulation. (B) Normalized quantification of NF- $k B$ protein members on TNF- $\alpha$ stimulation followed by double and triple treatments. Two-tailed student's $t$-test: $* P<0.05$; error bars represent \pm SD.

Abbreviations: ACA, acetoxychavicol acetate; CDDP, cisplatin; GAPDH, glyceraldehyde-3-phosphate dehydrogenase; MIP, Mycobacterium indicus pranii; NF- KB, nuclear factor kappa B; TNF- $\alpha$, tumor necrosis factor alpha.

dose intensity but also on the dose ratios of the combined components. Our results demonstrated that MIP:CDDP, MIP:ACA and MIP:ACA:CDDP combinations exhibited potent cytotoxicity in a synergistic manner against the majority of cancer cells tested. Despite displaying less cytotoxic effect with high doses in standalone treatments, double and triple combinations demonstrated synergistic inhibitory effect with reduced dosage of each drug and agent. It is also noteworthy to mention that the triple combination with reduced dosage at $\mathrm{IC}_{10}$ exerted synergism compared to higher dosage at $\mathrm{IC}_{25}$, which showed that the type of interaction is dependent on the concentration and ratio of combined drugs. ${ }^{29}$ These results demonstrate that better effects could be acquired in combination therapies with lower doses of each drug compared with higher doses. Similar effect was seen in glioma cells when camptothecin and doxorubicin were exposed at a molar ratio of 5:1, and a strong antagonism was observed, whereas a 1.5:1 ratio resulted in synergistic activity. ${ }^{30}$ Therefore, individual toxicities associated with higher doses could be reduced. Previously, MIP, ${ }^{28} \mathrm{ACA}^{27}$ and
$\mathrm{CDDP}^{31}$ as standalone treatments have been shown to induce apoptosis in cancer cells. As all standalone treatments were shown to induce apoptosis, the efficacy of apoptotic cell death in double and triple combinations was tested and shown to induce apoptosis in MCF-7 cells. Therefore, multiple drugs that target similar pathway can interact synergistically to achieve higher therapeutic efficacy and target selectivity with reduced individual drug dose. ${ }^{4}$

Disc diffusion assay is a well-established method to test interaction of drugs with bacteria through qualitative analysis. It offers many advantages: simplicity, low cost, the ability to test enormous numbers of microorganisms and antimicrobial agents, and the ease to interpret results provided. ${ }^{32}$ Generally, antimicrobial agent diffuses into the agar and inhibits germination and growth of the microorganism, which is shown by zone of inhibition. The diameter of the zone reflects the susceptibility of the bacteria and shows diffusion rate of the drug through the agar medium..$^{33}$ In this study, CDDP and ACA did not show inhibitory effect against MIP, which suggests that these drugs can be used together to obtain synergistic interaction. 
The constitutive activation of NF- $\mathrm{KB}$ is associated with the growth and survival of cancer cells. ${ }^{34}$ It was shown that combining an NF- $\mathrm{KB}$ inhibitor with an anticancer drug could enhance overall antitumor responses. ${ }^{35,36}$ Several studies have shown that chemoresistance is often contributed by activation of NF- $\kappa \mathrm{B}$ by chemotherapeutic agents. ${ }^{37}$ Thus, a strategic approach to tackle cancer development is to formulate an anticancer drug that targets NF- $\mathrm{KB}$ suppression. A previous study on ACA extracted from Malaysian ginger has shown its ability to induce apoptosis and suppress NF- $\mathrm{KB}$ activity through IKK $\alpha / \beta$ suppression in oral squamous cell carcinoma. ${ }^{12}$ In this study, combination treatment of MIP with ACA and CDDP has shown similar pattern in suppressing NF- $\mathrm{KB}$ activation.

On the other hand, MIP HKB was shown to inhibit NF- $\kappa B$ activation in melanoma cancer therapy ${ }^{38}$ Even though a number of studies have reported MIP as an immune stimulator with the ability to inhibit proliferation of cancer cells, the mechanism or mode of action was not reported..$^{22,23}$ In this study, we have shown that MIP in combination with ACA or/and CDDP was capable of inhibiting NF- $\mathrm{\kappa B}$ activation through blocking $\mathrm{p} 65$ cytoplasm translocation to the nucleus. As NF- $\mathrm{KB}$ plays an important role in various biologic processes including apoptosis, stress response, immunity and inflammation, the immune-potentiating effect of MIP together with NF- $\kappa B$ could enhance antitumor activity through the immune system.

Even though CDDP is a well-established drug in cancer treatment, ${ }^{39}$ its usage is often limited because of undesired side effects and tumor resistance that promote secondary malignancies. ${ }^{17,18}$ Thus, this commercial drug is often combined with other drugs to obtain positive outcomes with minimal side effects..$^{40} \mathrm{CDDP}$ was successfully paired with ACA to treat oral cancer xenograft with increased cytotoxic effect and minimal body weight loss in an animal model. ${ }^{12}$

Reports have shown that multitargeted therapies have a higher success rate in inducing cytotoxicity and tumor clearance compared with monotargeted therapies. Natural product, such as curcumin, is shown to enhance the effects of a chemotherapeutic drug, gemcitabine, by sensitizing human bladder cancer cell and it induces apoptotic effects through NF- $\kappa B$ inactivation. ${ }^{41}$ Similarly, $1^{\prime}$ S- $1{ }^{\prime}$-acetoxyeugenol acetate, an analog of ACA, in combination with paclitaxel chemosensitizes human breast cancer cells and enhances its apoptotic effects. ${ }^{42}$ Similarly, in this study, MIP:ACA:CDDP in combination was able to enhance cytotoxicity effects against cancer cells. Thus, it can serve as a promising candidate for further in vivo development in xenograft animal models to further validate its anticancer and immune-potentiating systemic effects.

\section{Conclusion}

Overall, the present study shows that MIP in combination with ACA and CDDP can inhibit the growth of various human cancers. The double and triple combination regimens had significant synergistic effects with $\mathrm{CI}$ values $<1$ on human breast cancer cells. Although in vitro models are not absolutely predictive of clinical activity, the current data could form the basis for further preclinical and clinical trials. These findings are important in the design of bacteriabased combination chemotherapy. Continued preclinical and clinical studies should provide further insights and assist in optimal combination.

\section{Acknowledgments}

This study was supported by grants from the Ministry of Science, Technology and Innovation (MOSTI) through the Science Fund (PROJECT NO 02-01-03-SF0863 and 02-0222-SF0011), and the UCSI University Pioneer Scientist Initiative Fund (PSIF) (Proj-In-FAS-041).

\section{Author contributions}

NHN conceived the entire study. MS carried out all experimental assays and drafted the manuscript. LSK carried out ACA standalone cytotoxicity test. All authors contributed toward data analysis, drafting and revising the paper and agree to be accountable for all aspects of the work.

\section{Disclosure}

The authors report no conflicts of interest in this work.

\section{References}

1. World Health Organization. [webpage on the Internet]. Cancer. Available from: http://www.who.int/mediacentre/factsheets/fs297/en/. Accessed 1 April 2017.

2. Humphrey RW. Opportunities and challenges in the development of experimental drug combinations for cancer. J Natl Cancer Inst. 2011;103(16): 1222-1226.

3. Sica DA. Fixed-dose combination antihypertensive drugs. Do they have a role in rational therapy? Drugs. 1994;48:16-24.

4. Lee JH, Nan A. Combination drug delivery approaches in metastatic breast cancer. J Drug Deliv. 2012;2012:17.

5. Szakacs G, Paterson JK, Ludwig JA, Booth-Genthe C, Gottesman MM. Targeting multidrug resistance in cancer. Nat Rev Drug Discov. 2006;5: 219-234.

6. Szakacs G, Paterson JK, Ludwig JA, Booth-Genthe C, Gottesman MM. Targeting multidrug resistance in cancer. Nat Rev Drug Discov. 2006; 5:219-234

7. Hasima NN, Aun LI, Azmi MN, et al. 1'S-1'-Acetoxyeugenol acetate: a new chemotherapeutic natural compound against MCF-7 human breast cancer cells. Phytomedicine. 2010;17:935-939.

8. Mitsui S, Kobayashi S, Nagahori S, Ogiso A. Constituents from seeds of Alpinia galanga Wild and their anti-ulcer activities. Chem Pharm Bull (Tokyo). 1985;24:2377-2382. 
9. Matsuda H, Pongpiriyadacha Y, Morikawa T, Ochi M, Yoshikawa M. Gastroprotective effects of phenylpropanoids from the rhizomes of Alpinia galanga in rats: structural requirements and mode of action. Eur J Pharm. 2003;471(1):59-67.

10. Itokawa H, Morita H, Sumitomo T, Totsuka N, Takeya K. Antitumour principles from Alpinia galangal. Planta Med. 1987;53:32-33.

11. Khalijah A, Azmi MN, Aun LI, Aziz AN, Ibrahim H, Nagoor NH. The apoptotic effect of 1'S-1'-acetoxychavicol acetate from Alpinia conchigera on human cancer cells. Molecules. 2010;15(11):8048-8059.

12. In LLA, Arshad NM, Ibrahim H, Azmi MN, Awang K, Nagoor NH. $1^{\prime}$-Acetoxychavicol acetate inhibits growth of human oral carcinoma xenograft in mice and potentiates cisplatin effect via pro-inflammatory microenvironment alterations. BMC Complement Altern Med. 2012;12:179.

13. Phuah NH, In LL, Azmi MN, Ibrahim H, Awang K, Nagoor NH. Alterations of MicroRNA expression patterns in human cervical carcinoma cells (CaSki) toward 1'S-1'-acetoxychavicol acetate and cisplatin. Reprod Sci. 2013;20(5):567-578.

14. Williams BA, Markrigiannis AP, Blay J, Hoskin DW. Treatment of the P815 murine mastocytoma with cisplatin or etoposide up-regulates cell-surface Fas (CD95) expression and increases sensitivity toanti-Fas antibody-mediated cytotoxicity and to lysis by anti-CD3-activated killer-T cells. Int J Cancer. 1997;73:416-423.

15. Andersson A, Fagerberg J, Lewensohn R, Ehrsson H. Pharmacokinetics of cisplatin and its monohydrated complex in humans. J Pharm Sci. 1996;85:824-827.

16. Ogawa M. Anticancer drugs and pharmacologic actions. Nippon Rinsho. 1997;55:1017-1023.

17. Tsang RY, Al-Fayea T, Au HJ. Cisplatin overdose: toxicities and management. Drug Saf. 2009;32:1109-1122.

18. Talwar GP. Towards development of a vaccine against leprosy. Introduction. Lepr India. 1978;50:492-497.

19. Nath I. A vaccine for leprosy. Nat Med. 1998;4:548-550.

20. Kharkar R. Immune recovery in HIV with Mycobacterium w. J Indian Med Assoc. 2002;100:578-579.

21. Rath N, Kar HK. Efficacy of intra dermal heat-killed Mycobacterium $w$ in psoriasis: a pilot study. Int J Dermatol. 2003;42:756-757.

22. Sur PK, Dastidar AG. Role of Mycobacterium $w$ as adjuvant treatment of lung cancer, non-small cell lung cancer. J Indian Med Assoc. 2003;101:118-120.

23. Chaudhuri P, Mukhopadhyay S. Bladder preserving approach for muscle invasive bladder cancer-role of Mycobacterium w. J Indian Med Assoc. 2003;101:559-560.

24. Subramaniam M, In LL, Kumar A, Ahmed N, Nagoor NH. Cytotoxic and apoptotic effects of heat killed Mycobacterium indicus pranii (MIP) on various human cancer cell lines. Sci Rep. 2016;6:19833.

25. Chou TC, Talalay P. Quantitative analysis of dose-effect relationships: the combined effects of multiple drugs or enzyme inhibitors. Adv Enzyme Regul. 1984;22:27-55.

26. Koay DC, Zerillo C, Narayan M, Harris LN, DiGiovanna MP. Antitumor effects of retinoids combined with trastuzumab or tamoxifen in breast cancer cells: induction of apoptosis by retinoid/trastuzumab combinations. Breast Cancer Res. 2010;12(4):R62.

27. Awang K, Azmi MN, Aun LI, Aziz AN, Ibrahim H, Nagoor NH. The apoptotic effect of 1's-1'-acetoxychavicol acetate from Alpinia conchigera on human cancer cells. Molecules. 2010;15(11):8048-8059.
28. Pandey RK, Bhatt KH, Dahiya Y, Sodhi A. Mycobacterium indicus pranii supernatant induces apoptotic cell death in mouse peritoneal macrophages in vitro. PLoS One. 2011;6(2):e17093.

29. Mayer LD, Harasym TO, Tardi PG. Ratiometric dosing of anticancer drug combinations: controlling drug ratios after systemic administration regulates therapeutic activity in tumor-bearing mice. Mol Cancer Ther. 2006;5(7):1854-1863.

30. Pavillard V, Kherfellah D, Richard S, Robert J, Montaudon D. Effects of the combination of camptothecin and doxorubicin or etoposide on rat glioma cells and camptothecin-resistant variants. Br J Cancer. 2001;85: 1077-1083.

31. Brozovic A, Osmak M. Activation of mitogen-activated protein kinases by cisplatin and their role in cisplatin-resistance. Cancer Lett. 2007;251(1):1-16.

32. Balouiri M, Sadiki M, Ibnsouda SK. Methods for in vitro evaluating antimicrobial activity: a review. J Pharm Anal. 2016;6(2):71-79.

33. Reller LB, Weinstein M, Jorgensen JH, Ferraro MJ. Antimicrobial susceptibility testing: a review of general principles and contemporary practices. Clin Infect Dis. 2009;49(11):1749-1755.

34. Guttridge DC, Albanese C, Reuther JY, Pestell RG, Baldwin AS Jr. NF- $\kappa \mathrm{B}$ controls cell growth and differentiation through transcriptional regulation of cyclin D1. Mol Cell Biol. 1999:5785-5799.

35. Bauer JA, Lupica JA, Schmidt H. Nitrosylcobalamin potentiates the anti-neoplastic effects of chemotherapeutic agents via suppression of survival signaling. PLoS One. 2007;2:e13132007.

36. Chawla SM, Bauer JA, Lupica JA, et al. Suppression of NF-kappa B survival signaling by nitrosylcobalamin sensitizes neoplasms to the anti-tumour effects of Apo2L/TRAIL. J Biol Chem. 2003;278: 39461-39469.

37. Nakanishi C, Toi M. Nuclear factor-kappaB inhibitors as sensitizers to anticancer drugs. Nat Rev Cancer. 2005;5:297-309.

38. Halder K, Banerjee S, Ghosh S, et al. Mycobacterium indicus pranii $(\mathrm{Mw})$ inhibits invasion by reducing matrix metalloproteinase (MMP-9) via AKT/ERK-1/2 and PKC $\alpha$ signalling: a potential candidate in melanoma cancer therapy. Cancer Biol Ther. 2017;18(11):850-862.

39. Gebbia V, Mantovani G, Farris A, et al. Vinorelbine, cisplatin, and 5-fluorouracil as initial treatment for previously untreated, unresectable squamous cell carcinoma of the head and neck: result of a phase II multicenter study. Cancer. 1997;79:1394-1400.

40. Florea A, Büsselberg D. Cisplatin as an anti-tumor drug: cellular mechanisms of activity, drug resistance and induced side effects. Cancers (Basel). 2011;3:1351-1371.

41. Kamat AM, Sethi G, Aggarwal BB. Curcumin potentiates the apoptotic effects of chemotherapeutic agents and cytokines through down-regulation of nuclear factor-kappaB and nuclear factor-kappaB-regulated gene products in IFN-alpha-sensitive and IFN-alpha-resistant human bladder cancer cells. Mol Cancer Ther. 2007;6:1022-1030.

42. In LLA, Azmi MN, Ibrahim H, Awang K, Nagoor NH. 1'S-1' Acetoxyeugenol Acetate (AEA): a novel phenolpropanoid from Alpinia conchigera enhances the apoptotic effects of paclitaxel in MCF-7 cells through nuclear factor kappa-B inactivation. Anticancer Drugs. 2011;22:424-434. 


\section{Supplementary material}

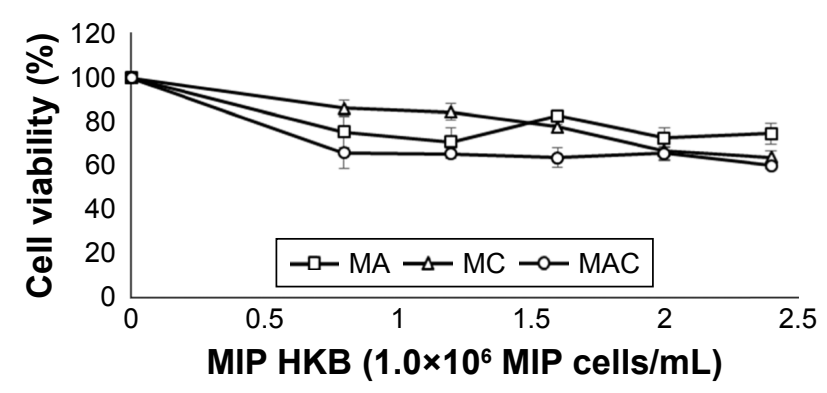

Figure SI Cytotoxicity of MIP HKB at 24 hours in normal human breast epithelial, MCF-IOA by the MTT assay.

Notes: MA represents MIP:ACA; MC represents MIP:CDDP; and MAC represents MIP:ACA:CDDP. Data were represented as mean \pm SD of three independent experiments. MIP:ACA and MIP:CDDP combination therapy achieved $60 \%$ cell viability while MIP:ACA:CDDP therapy shows $65 \%$ cell viability in normal human breast epithelial, MCF-IOA at 24-hour treatment.

Abbreviations: ACA, acetoxychavicol acetate; CDDP, cisplatin; HKB, heat-killed bacteria; MIP, Mycobacterium indicus pranii.

\section{Publish your work in this journal}

Drug Design, Development and Therapy is an international, peerreviewed open-access journal that spans the spectrum of drug design and development through to clinical applications. Clinical outcomes, patient safety, and programs for the development and effective, safe, and sustained use of medicines are the features of the journal, which has also been accepted for indexing on PubMed Central. The manuscript management system is completely online and includes a very quick and fair peer-review system, which is all easy to use. Visit http://www.dovepress.com/testimonials.php to read real quotes from published authors.

Submit your manuscript here: http://www.dovepress.com/drug-design-development-and-therapy-journal 